\title{
Customer Satisfaction toward Online Purchasing Services: Evidence from Small and Medium Restaurants
}

\author{
Carol Y. Lu ${ }^{\mathrm{a}}$, Dwi Suhartanto ${ }^{\mathrm{b} *}$, Arie Indra Gunawan ${ }^{\mathrm{c}}$, and Brendan T Chen ${ }^{\mathrm{d}}$ \\ a Associate Professor, Department of International Business, Chung Yuan Christian University, \\ Taiwan \\ ${ }^{\mathrm{b}}$ Professor, Department of Business Administration, Politeknik Negeri Bandung, Indonesia \\ Lecturer, Department of Business Administration, Politeknik Negeri Bandung, Indonesia \\ ${ }^{\mathrm{d}}$ Professor, Department of Leisure Industry, National Chin-Yi University of Technology, Taiwan
}

Received 15 December 2019; accepted 9 January 2020

\begin{abstract}
This study examines shopper satisfaction with respect to online shopping in small and medium-sized restaurants (SMRs), with the quality of e-service and food as the determinants. For this research purpose, the study gathered 392 data items from online restaurant shoppers in Bandung, Indonesia. Then Structural Equation Modeling (PLS) was adopted to evaluate the relation between customer satisfaction and its hypothesized determinants. The results reveal that the quality of e-service and the quality of food are essential determinants of customer satisfaction, and that perceived value partially mediates the relationship between these two determinants and customer satisfaction. This study offers a guide to SMR managers to enhance their business performance by focusing on food quality and eservice quality. In terms of online service-based businesses, this research implies that SMRs need to collaborate with reliable online platform service providers.
\end{abstract}

\section{KEYWORDS}

Satisfaction

The quality of e-service

The quality of food

Online Services

\section{INTRODUCTION}

Advancements in online-based technology have resulted in shifts in the retailing industry, affecting both customers and business practice (Suhartanto \& Leo, 2018). The development of Internet technology has enabled customers to access online customer reviews and organize information to enhance their shopping experience. This technology allows customers to compare prices and shop conveniently (Chang, Chou \& Lo, 2014; Yeo, Goh \& Rezaei, 2017). In the case of the restaurant industry, the existence of online based technology has boosted food purchasing, whether through the website of a restaurant or other online venues. Online technology allows restaurants not only to develop their market (Ng, Wong, \& Chong, 2017; Yeo et al., 2017), but also to increase productivity, order accuracy, and establish a relationship with their customers (Kimes, 2011). Many customers now find shopping for food more pleasant than shopping for other items and this trend is proliferating (Chang et al., 2014; Lin, Ortega, \& 
Caputo, 2018). Consequently, many restaurants face fierce competition, which presents both an opportunity and a challenge. In this new online environment, the ability to satisfy customer needs is more important than ever (Pee, Jiang \& Klein, 2018; Pham \& Ahammad, 2017).

The importance of customer satisfaction and its determinants has been widely discussed in the extant literature. As studies show, key elements of customer satisfaction are product quality, service, and value (Namkung \& Jang, 2007; Suhartanto et al., 2018). However, due to differences among businesses and industries, it is challenging to extend the research findings of one study to another. Some scholars (Abou-Shouk \& Khalifa, 2017; Caruana \& Ewing, 2010) state that the creation of satisfaction is still not fully understood. Thus, when attempting to understand the determinants of customer satisfaction, it is essential to examine satisfaction creation in different sectors of the target industry. Online shopping is a new-born industry with great future promise ( $\mathrm{Ng}$ et al., 2017; Pigatto, Machado, Negreti, \& Machado, 2017). Surprisingly, the literature seems almost silent regarding the drivers of online shopping (Nisar \& Prabhakar, 2017; Pham \& Ahammad, 2017), and the determinants of customer satisfaction, specifically in restaurants, are still not well understood. Therefore, developing a customer satisfaction model that addresses the antecedents and outcomes of online restaurant shopping remains a worthwhile endeavor (Chang et al., 2014; Trivedi \& Yadav, 2018).

Concerning these gaps, this study examines the determinants of online purchasing in small and medium-sized restaurants, as well as the customer satisfaction outcomes. More specifically, this study proposes to evaluate the perceived quality of e-service, quality of food, and value in online restaurant shopping. Despite the growth of the restaurant industry (Han \& Hyun, 2017), self-owned restaurants, especially small and medium-sized ones, often find it difficult to compete with traditional restaurants, which are typically able to offer more menu choices (Pham \& Ahammad, 2017). The findings of this study may help food business managers in the online, self-owned restaurant industry create a more sustainable business strategy.

\section{CONCEPTUAL FRAMEWORK AND HYPOTHESES}

\section{Shopper Satisfaction toward Restaurant Online Purchasing}

In the competitive restaurant industry environment, satisfying customers is the key to business survival and success (Ha \& Jang, 2010). While there are many definitions of customer satisfaction, Oliver's (1999) definition is cited most often in the literature: a "consumer's fulfillment response" is a "a satisfaction judgment [that] involves at the minimum two stimuli: an outcome and a comparison referent." As this definition implies, customers are most likely to report satisfaction if the product or service performance exceeds their expectations. Current studies on customer satisfaction in several industries suggest that consumer satisfaction is influenced by physiological and psychological dynamics occurring in a multi-dimensional space (Suhartanto et al., 2018). E-satisfaction, for example, implies a subjective comparison of e-retail to conventional retail experience that involves largely undisclosed feelings and reactions. Similarly, customer satisfaction with online restaurant shopping is a subjective assessment of the online purchasing service based on, among other factors, the customer's prior experience of shopping.

The concept of satisfaction has been broadly examined in many retail studies. With respect to online businesses, an examination of consumer satisfaction determinants is increasing (Pham 
\& Ahammad, 2017). Recently, several studies (Pee et al., 2018; Yeo et al., 2017) have discussed the impact of website attributes on shopper satisfaction. Earlier studies successfully identified several important website factors that are essential to helping $\mathrm{B} 2 \mathrm{C}$ online businesses. However, scholars are not yet in agreement on how these factors influence customer satisfaction (Nisar \& Prabhakar, 2017). Several recent studies have examined online service quality (Jeon \& Jeong, 2017; Pee et al., 2018), purchasing behavior (Pham \& Ahammad, 2017), consumer spending (Nisar \& Prabhakar, 2017), consumer group buying (Chang et al., 2014) and e-retail quality (Kim, Jin, \& Swinney, 2009). While these studies offer a general basis for determining the antecedents of consumer satisfaction in online purchasing, they are unable to disclose the factors that determine customer satisfaction with online restaurants. Additionally, most prior studies pay scant attention to the post-consumption period, as the primary focus is on evaluating e-satisfaction in the shopping and pre-shopping stages (Pham \& Ahammad, 2017).

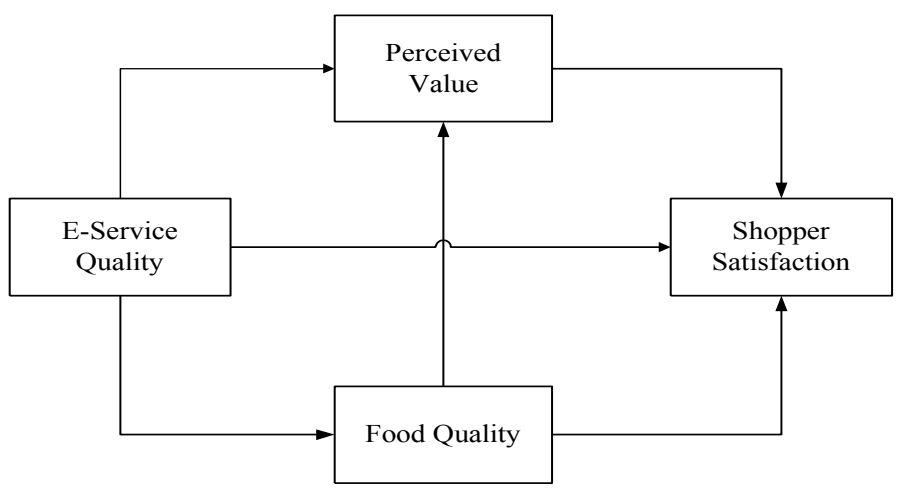

Figure 1. Shopper satisfaction toward online restaurant purchasing model

In the context of online purchasing, Hsin and Wang (2011) contended that the quality of eservice is the key driver of value proposition and customer satisfaction. They conclude that the level of e-service is the determining factor of satisfaction, which they identify as an emotional reaction to consuming a particular product or service. This finding is in line with Fornel et al.'s (1996) model of the American Customer Satisfaction Index (Stokes \& Frederick-Recascino), which indicates that the quality of a service has a more significant influence on customer satisfaction than price or value. More recent service studies support this finding (Chang, Wang, \& Yang, 2009; Jeon \& Jeong, 2017; Nisar \& Prabhakar, 2017; Pham \& Ahammad, 2017). However, with respect to online shopping, and the study of Hsin and Wang (2011) in particular, a comprehensive interpretation of the determinants of customer satisfaction is lacking, since product factors are not taken into account. This makes it difficult to extend the existing findings to the restaurant industry, where food and beverages are essential factors in shaping customer experiences (Fandos \& Flavián, 2006; Han \& Hyun, 2017). Nisar and Prabhakar (2017) reported that to create a thriving online business, as well as reach a high level of customer satisfaction, eretailers should pay attention to both service quality and product quality. Hence, we attempt to consider both in our study of customer satisfaction with respect to online food purchases. 


\section{The Impact of the Quality of E-Service toward Shopper Satisfaction}

The most common definition used to explain Internet service quality is "the extent to which a website facilitates efficient and effective shopping, purchasing, and delivery of products and services" (Zeithaml et al., 2002). Several studies show that keeping up a high-quality e-service is fundamental to the success of an online company (Parasuraman, Zeithaml \& Malhotra, 2005; Chang et al., 2014; Jeon \& Jeong, 2017; Pee et al., 2018) The latest research indicates that the quality of an e-service is mainly linked to website quality and web services (Pigatto et al., 2017). Shoppers are most likely to require a high level of e-service quality when they are making online purchases (Caruana \& Ewing, 2010). Therefore, providing high-quality websites and Internetbased applications is vital to achieving a successful marketing strategy. This strategy is essential in technology-based businesses such as online restaurants, where the customer and the firm interact mostly through Internet-based devices or the firm's website. Jeon and Jeong (2017) suggested that enabling an excellent online application and website is crucial to enhancing customer retention, increasing the number of revisits to the website, and ensuring continued loyalty.

In online business, a creative, advanced website and online applications are equal to an outstanding supply chain in traditional business. Current research on the quality of e-service mostly concentrates on dimensionality, including its antecedents and consequences. Parasuraman and colleagues (2005) carried out an important study on e-service dimensionality with the measurement scale of the quality of e-service named "ES-QUAL." Their study shows that the quality of e-service has four dimensions: system accessibility, effectiveness, confidentiality, and fulfillment. Although some more recent studies have increased the number of dimensions to the estimation of e-service quality (such as Change et al., 2009), ES-QUAL remains the most widely accepted model (Hsin \& Wang, 2011; Nguyen, Leeuw \& Dullaert, 2018). As this model shows, the quality of an e-service needs to be considered when establishing an online business, since quality and its constituent dimensions have an important influence on customer satisfaction. In line with this statement, we propose the following hypothesis:

$\mathrm{H}_{1}$ : The quality of e-service positively influences shopper satisfaction.

\section{The Impact of the Quality of Food on Shopper Satisfaction}

The quality of food is widely acknowledged as an essential factor in determining the level of customer satisfaction in a restaurant (Ha \& Jang, 2010). While many scholars refer to the importance of food quality, they have tended in the past to view it as an undifferentiated component of customer satisfaction. Exceptions are Ha and Jang (2010), who use the attributes of flavor, nutrition, and variety to evaluate the impact of food quality on a customer's experience and willingness to revisit the restaurant. More recently, Liu et al. (2017) referred to menu, display, size, and variation in their evaluation of food quality.

Some scholars (Sulek \& Hensley, 2004) suggest that customers often base their evaluation of food quality on the perception of its safety, appeal, and dietary value. Other scholars (Namkung \& Jang, 2007) propose that menu variation, healthiness, food display, freshness, taste, and the temperature of food are the determining factors of food quality. Regardless of how foodservice and the quality of food are defined, they are considered essential elements that affect a customer's experience with a restaurant (Liu et al., 2017). 
Most recent studies on restaurants empirically evaluate the quality of food because of its fundamental role in influencing customer satisfaction. Liu et al. (2017) suggested that the quality of food is the primary factor determining a customer's choice of restaurant. Regarding hotel restaurants, Han and Hyun (2017) maintained that the quality of food is the key determinant of customer retention. Sulek and Hensley (2004) stated that food quality has a greater effect on customer satisfaction in a restaurant than does service quality and the ambience of the restaurant. In yet another study, Namkung and Jang (2007) find that food quality has a critical role in influencing customer satisfaction, the propensity to revisit, and the endorsement of a restaurant. Finally, Nisar and Prabhakar (2017) reported that product quality is a key determinant of customer satisfaction with online purchases. Based on these studies, it is reasonable to assume that food quality will be a key determinant of customer satisfaction when making a purchase in an online restaurant.

$\mathrm{H}_{2}$ : The quality of food significantly influences shopper satisfaction.

The Influence of the Quality of E-Service on the Quality of Food Assessment

The links among quality of service, food quality, and e-service have been widely explored in restaurant literature (Ha \& Jang, 2010; Kedah, Ismail, Haque, \& Ahmed, 2015). However, the impact of e-service quality on the assessment of food quality has seldom been examined. According to the Spillover theory, experience in one area of life often influences other areas (Sirgy, Efraty, Siegel \& Lee, 2001). According to this theory, the experience of customers in one phase of the consumption process will influence their experience in subsequent phases. Following the service process model, de Ruyter, et al. (1997) maintain that customers attitudes toward food purchased are influenced by their online service experience, including the placement of the order. Stated differently, the quality of e-service affects the perceived quality of food.

$\mathrm{H}_{3}$ : The quality of e-service significantly influences the quality of food evaluation.

\section{The Mediation Role of Perceived Value}

Caruana and Ewing (2010) suggested that online businesses have a competitive advantage due to the low cost of online marketplaces. The expectation of cost reduction also increases the propensity of online shoppers to compare products or services they buy in terms of prices and benefits. Therefore, online businesses need to have a high perceived value. The link between eretailers and customers is stronger if the customer perceives that the value of the product purchased is more than worth the time and cost involved. Research has shown the influence of online service and product quality on perceived value (Caruana \& Ewing, 2010; Jeon \& Jeong, 2017). Since research findings indicate an immediate impact of perceived value on customer satisfaction, this paper suggests that the link between, on the one hand, customer satisfaction and, on the other hand, e-service quality and food quality, is mediated by perceived value.

$\mathrm{H}_{4}$ : The link between the quality of e-service and shopper satisfaction is mediated by perceived value.

$\mathrm{H}_{5}$ : The link between the quality of food and shopper satisfaction is mediated by perceived value. 


\section{RESEARCH METHODS}

Many studies have been conducted that examine e-service quality, although as far as the author is aware, none of these studies focus on online restaurants. This study adopts the work of Parasuraman's (2005) ESQUAL model, which evaluates efficiency, fulfillment, privacy, and system availability with ten indicators, to measure customer satisfaction in online restaurants as influenced by e-service quality and food quality. The reason this model is adopted in this study is due to its wide use in related studies (Hsin \& Wang, 2011; Nguyen et al., 2018). Borrowing from other studies, the current study anchors the quality of food on four items: diversity, taste, appeal, and fitness (Ha \& Jang, 2010; Namkung \& Jang, 2007). Three items are used to measure perceived value: affordable price, overall ease of website use, and the cost-benefit ratio (Caruana \& Ewing, 2010; Hsin \& Wang, 2011). Shopper satisfaction is measured by comparing expectation to overall satisfaction (Suhartanto, 2016). The quality of e-service, food quality, perceived value, and customer satisfaction are measured using a Likert scale (1 strongly disagree to 5 strongly agree). Prior to the study, a pre-test on 20 online restaurant shoppers was conducted to ensure that the questions and instructions were fully understood; the results were largely positive, although minor changes were made to the wording of several questionnaire items to improve their comprehensibility.

According to a report by Statista (2018), there is a significant customer segment in Indonesia for the online food delivery business, with approximately US\$ 968 million value transactions in 2018. The players in the online food business in Indonesia are dominated by international restaurants such as McDonald's, Pizza Hut, and Kentucky Fried Chicken, and they use online delivery services, such as GoFood and GrabFood. The competition among these businesses is intense, indicating an increasing demand for food through online delivery services, and a need for studying customer satisfaction with online restaurant purchasing services in the Indonesian market.

The focus of this study is customer behavior related to food purchases in small and medium-sized restaurants via their online devices in the Indonesian market. Since obtaining a comprehensive list of the online population of restaurant customers is nearly impossible, the study adopts convenience sampling rather than the probabilistic sampling method. Convenience sampling enables researchers to compile an accessible population sample (Zikmund, Babin, Carr \& Griffin, 2013). The data from the shoppers of online restaurant purchasing services was collected in Bandung during November and December 2017 by using a self- administered questionnaire. Among the 425 participants who were recruited, 392 were able to complete the questionnaires. Therefore, we had a minimum of 10 respondents for each questionnaire item, which fulfilled the requirement for structural equation modeling (Chin, 1998). The confidence level was at $95 \%$ and the error margin was $\pm 5 \%$, meeting the requirement for 340 samples, as suggested by Zikmund et al. (2013).

This study employed two stages for the data analysis process. First, variance-based Partial Least Squares (PLS) to assess the construct reliability and validity in evaluating measurement model. Second, validate the structural model and confirm the proposed hypotheses also by the use of PLS. The reason for employing PLS for analyzing the data is that it is a suitable method to evaluate the latent constructs used in this research. Furthermore, this method enable the researcher to use a small and medium sample size, and the data distribution is not normal (Chin, Peterson, \& Brown, 2008) as it also happen in this research. Therefore, PLS was 
employed because of its ability to estimate the holistic coefficient paths in a complex structural models (Hair, Hult, Ringle, \& Sarstedt, 2017).

\section{RESULTS}

Table 1 shows that most of respondents on this study are female customers and young customers with the age less than 30 years old. These demographic results are coherent with the other studies on online food (Chang et al., 2014; Kedah et al., 2015).

\section{Table 1. Respondents' demographics}

\begin{tabular}{lccc}
\hline Variable & Description & Frequency & $\%$ \\
\hline Gender & Male & 111 & $29 \%$ \\
Age & Female & 281 & $71 \%$ \\
& $17-20$ & 114 & $29 \%$ \\
& $21-30$ & 264 & $68 \%$ \\
Occupation & $31-40$ & 8 & $2 \%$ \\
& Over 40 & 6 & $2 \%$ \\
& Student & 9 & $2 \%$ \\
& University student & 278 & $76 \%$ \\
& Worker & 96 & $20 \%$ \\
& Housewife & 25 & $0 \%$ \\
& Others & 3 & $1 \%$ \\
\hline
\end{tabular}

\section{Measurement Model}

To analyze the validity of the overall construct, this research evaluated factor loading, composite reliability (CR), and average variance extracted (AVE); Table 2 shows that the overall indicators of validity resembled with recommended cut-off value, with factor loading over o.6, composite reliability over 0.7, and AVE over 0.5 (Chin et al., 2008; Hair, Black, Babin, \& Anderson, 2010).

Hahn et al.'s (2017) suggest that the measurement of the quality of e-service that uses the approach of the second-order will enable a thorough understanding of the quality of e-service. Concerning their finding, this study used the construct of the quality of e-service as a second order, which consist of efficiency, fulfilment, privacy, and system availability. Reliability test results in the factor loading value ranging are from 0.815 to 0.897 , that all significant at $\mathrm{p}<0.01$. The AVE value (0.726), CR value (0.914), and Cronbach's Alpha (0.876) with the construct of the quality of e-service exceed the recommended levels, which mean that the construct of the second order the quality of e-service considered reliable and valid.

Henseler et al. (2015) suggest employing the Heterotrait-Monotrait method to evaluate the discriminant validity of the construct with less than 0.9 cuts off value. Based on this suggestion, the discriminant validity of the constructs evaluated in this research is qualified as all values of the Heterotrait-Monotrait are no more than o.9. These results conclude that the discriminant validity between the overall variable constructs is qualified. 
Table 2. Loading of the item measurement model, CR, and AVE

\begin{tabular}{|c|c|c|c|c|}
\hline Variable/Indicator & Loading & Cronbach $\alpha$ & CR & AVE \\
\hline The quality of E-Service & & 0.876 & 0.914 & 0.726 \\
\hline Informative & 0.823 & & & \\
\hline Easy to use & 0.840 & & & \\
\hline Well structured & 0.800 & & & \\
\hline On time delivery order & 0.817 & & & \\
\hline Right time delivery & 0.718 & & & \\
\hline Quick order delivery & 0.707 & & & \\
\hline Shopping information security & 0.923 & & & \\
\hline Private concern on shopper personal info & 0.940 & & & \\
\hline Always available & 0.809 & & & \\
\hline Not crash & 0.768 & & & \\
\hline The quality of food & 0.884 & 0.697 & 0.803 & 0.509 \\
\hline Menu variety & 0.742 & & & \\
\hline Healthy food option & 0.654 & & & \\
\hline Food freshness & 0.752 & & & \\
\hline Food presentation & 0.745 & & & \\
\hline Food taste & 0.764 & & & \\
\hline Perceived Value & & 0.843 & 0.905 & 0.760 \\
\hline Offers affordable price & 0.861 & & & \\
\hline Overall user convenience & 0.869 & & & \\
\hline Cost-benefit ratio of transaction & 0.886 & & & \\
\hline Shopper Satisfaction & & 0.899 & 0.952 & 0.908 \\
\hline Desirable experience & 0.950 & & & \\
\hline Fully satisfied & 0.956 & & & \\
\hline
\end{tabular}

\section{Structural Model}

The second analysis evaluated the structural model and tested the developed hypotheses. The path coefficients evaluation, as Chin et al. (2008) suggest, conducted by using an iteration in the bootstrapping procedure. The result of Goodness of Fit ( $\mathrm{GoF})$ evaluation shows the value of the model tested is 0.657 , meaning that the fitness of the model used in this study is good. Furthermore, normal fit index (NFI) and standardized root mean square residual (SRMR) employed to test the approximate fit indices. The results shows that the SRMR value is 0.089 (less than the proposed value of 0.8 ) and NFI value of 0.390 (less that the suggested level of 0.9), to demonstrate the fitness of the model (Hair et al., 2017).

Following the assessment of goodness of fit, the evaluation of hypothesized relationships conducted; as the result is shown in Table 3. The corrected $\mathrm{R}^{2} \mathrm{~S}$ able to explains the suggested constructs. The result shows that the quality of e-service value of $47.5 \%\left(R^{2}: 0.475\right)$ the quality of food. Both the quality of e-service and food shows $68.6 \%\left(R^{2}:\right.$ o.686) of perceived value, while the value of overall satisfaction determinants (the quality of e-service, food, and perceived value) of 50.5\% (R2: 0.505 ) of shopper satisfaction. As the $R^{2}$ ranged between 0.475 to 0.686 , 
the formation model of shopper satisfaction formation toward online food purchasing is valid (Chin et al., 2008).

Table 3 shows the significance test on the overall tested variable in this research. Based on the $t$-values of the direct effect column, the quality of e-service strongly influences satisfaction ( $\beta$ : 368 ) and the quality of food ( $\beta$ : o.689), which means hypotheses $\mathrm{H} 1 \mathrm{H}$ and $\mathrm{H} 2$ are accepted. The influence of the quality of food on satisfaction is also significant $(\beta: 0.222)$ which provide the acceptance for hypothesis $\mathrm{H}_{3}$. In addition, this study suggests that even though the quality of e-service and food has significantly influence shopper satisfaction, the influence of the quality of e-service is higher than the quality of food.

Table 3. The direct, indirect, and total effect of variable

\begin{tabular}{lcccccc}
\hline \multicolumn{1}{c}{ Path } & \multicolumn{2}{c}{ Direct } & \multicolumn{2}{c}{ Indirect } & \multicolumn{2}{c}{ Total Effect } \\
& $\beta$ & t-value & $\beta$ & t-value & $\beta$ & t-value \\
\hline The quality of e-service - Satisfaction & 0.368 & $4.075^{* *}$ & 0.309 & $3.774^{* *}$ & 0.677 & $16.037^{* *}$ \\
The quality of e-service - The quality of food & 0.689 & $18.223^{* *}$ & - & - & 0.689 & $18.223^{* *}$ \\
The quality of e-service - Perceived Value & 0.687 & $15.196^{* *}$ & 0.130 & $3.515^{* *}$ & 0.817 & $39.304^{* *}$ \\
The quality of food - Satisfaction & 0.222 & $3.551^{* *}$ & 0.036 & $2.003^{*}$ & 0.258 & $4.111^{* *}$ \\
The quality of food - Perceived Value & 0.189 & $3.607^{* *}$ & - & - & 0.189 & $3.607^{* *}$ \\
Perceived Value - Satisfaction & 0.191 & $2.208^{*}$ & - & - & 0.191 & $2.208^{*}$ \\
\hline
\end{tabular}

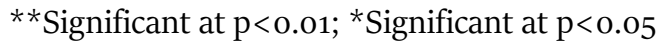

The relationships between the tested variables are depicted in Figure 2.

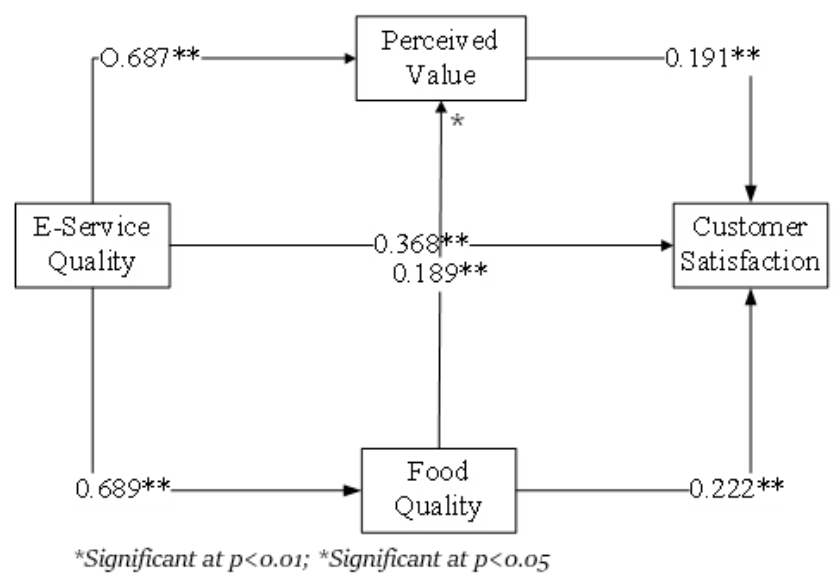

Figure 2. Relationship diagram

\section{Mediation Test}

To examine the perceived value mediation role (Hypotheses $\mathrm{H}_{4}$ and $\mathrm{H}_{5}$ ), this study follows Preacher and Hayes' (2004) suggestion, this study employed the Bootstrap method with biascorrected confidence estimate with a $95 \%$ confidence interval and 5000 bootstraps resamples. Table 4 provide the mediation test result.

Table 4 shows that shopper perceived value mediates the connection between the quality of e-service and shopper satisfaction. This mediation is indicated with the value of Bootstrap (o.o49) and confidence interval greater than o. Correspondingly, the mediation of perceived value on the link between the quality of food and shopper satisfaction is also verified, as the Bootstrap value is 0.037 and the confidence interval values of are between 0.011 and o.066. 
Table 4 shows that the relationship model between shopper satisfaction and the quality of eservice with perceived value has a coefficient value of 0.478 , which is less than the model with no perceived value mediation (o.671). Similarly, the coefficient value of the quality of food and satisfaction path with mediation (0.318) is less than the model without perceived value mediation (o.584). The decrease of path value coefficients indicates that Hypotheses $\mathrm{H}_{4}$ and $\mathrm{H}_{5}$ are partially accepted

Table 4 . The perceived value mediation test result

\begin{tabular}{|c|c|}
\hline Variable \& relationship & Value \\
\hline \multicolumn{2}{|l|}{ The quality of e-service and shopper satisfaction } \\
\hline The quality of e-service - Perceived value & $0.244^{* *}$ \\
\hline Perceived value - Satisfaction & $0.826^{* *}$ \\
\hline The quality of e-service - Satisfaction ${ }^{1)}$ & $0.671^{* *}$ \\
\hline The quality of e-service - Satisfaction ${ }^{2)}$ & $0.478^{* *}$ \\
\hline Bootstrap Value & 0.049 \\
\hline Confidence Interval & 0.011 to 0.075 \\
\hline \multicolumn{2}{|l|}{ The quality of food and shopper satisfaction } \\
\hline The quality of food Perceived value & $0.581^{* *}$ \\
\hline Perceived value - Satisfaction & $0.454^{* *}$ \\
\hline The quality of food - Satisfaction ${ }^{1}$ & $0.584^{* *}$ \\
\hline The quality of food Satisfaction ${ }^{2)}$ & $0.318^{* *}$ \\
\hline Bootstrap Value & 0.037 \\
\hline Confidence Interval & 0.011 to 0.075 \\
\hline
\end{tabular}

${ }^{1)}$ Without mediation, ${ }^{2)}$ With mediation, ${ }^{* *}$ significant at $\mathrm{p}<0.01$

\section{DISCUSSION}

This research contributes to the body of knowledge on the antecedents and consequences of customer satisfaction with online food purchasing services. The research indicates that strong relationships exist among the quality of e-service, food quality, customer satisfaction, and perceived value, and it highlights the critical role of quality in both e-service and food as these relate to customer satisfaction. These findings support the current understanding (Namkung \& Jang, 2007; Ryu \& Han, 2009; Hsin \& Wang, 2011; Chang et al., 2014; Nisar \& Prabhakar, 2017). The research extends the current model of the link between quality and satisfaction (Chang et al., 2009; Kedah et al., 2015; Pham \& Ahammad, 2017), and suggests that satisfied shoppers are more likely recommend and repurchase from an online restaurant than unsatisfied shoppers.

In addition, this study also suggests that the influence of both the quality of e-service and the quality of food on customer satisfaction is at least partially mediated by perceived value, and their effects are unbalanced: the overall effect of e-service exerts a stronger influence on customer satisfaction than food quality. This finding differs from Ha and Jang's study (2010), which reports that the quality of food has a direct influence on customer satisfaction with a restaurant, and its influence outweighs other elements, such as restaurant ambience. Their study focused on brick-and-mortar ethnic restaurants, whereas the current study focuses on online restaurants, which might account for the different findings. Moreover, it is also possible, as the following paragraph will show, that customers in online restaurants base their evaluation 
of the food on the e-service; this would result in a higher importance ranking for e-service quality than food quality. However, regardless of the reason for the present finding, this study indicates that in developing customer satisfaction, restaurants offering food online must focus on e-service. Thus, having a well-developed, informed website and an online application is a must.

Lastly, this study suggests a significant relationship exists between the quality of e-service and the quality of food. The results indicate that the quality of e-service has a positive influence on the quality of food, a finding that supports the service process model (de Ruyter et al., 1997). In online food purchasing, even though the food itself is perceived to be the most important factor in satisfying the customer's need, the food consumption process starts when the customer opens the online application or website to search for and order the food. This means that the web quality experience probably influences the customer's perception of the food quality. This result is coherent with Namkung \& Jang (2007) and Ryu \& Han (2009), which focus on conventional restaurants; as these studies find, the way a service is delivered affects the customers' food experience. From a theoretical stance, the significant relationship between eservice quality and food quality, indicated by the current study, provides support to the spillover theory in the online restaurant purchasing service.

\section{MANAGERIAL IMPLICATION}

A high quality of food and service in the restaurant businesses is essential to meeting customer expectations, but perhaps especially so in online food purchasing services. Developing high quality e-services and high quality food might be especially challenging for small and mediumsized restaurants, which do not have the resources of larger restaurants. This study concludes that SMRs need to be especially vigilant in developing strong cooperation with an online platform service provider, which can provide online delivery services. Selecting a favorable industry that runs a reliable delivery system is essential to establishing a high quality e-service in the perception of online shoppers.

While this study emphasizes the critical role of e-service quality in determining customer satisfaction toward online restaurant purchasing services, food quality also plays a role, since it affects perceived value. Therefore, this study suggests that SMR managers should strive to uphold high-quality food to increase customer satisfaction in their restaurants. The attractiveness, taste, variety, and healthiness of the food are crucial and should be wellpresented in the online application to be delivered to shoppers.

\section{LIMITATION AND FUTURE RESEARCH}

Even though this study contributes to the current research on the determinants of customer satisfaction in online purchasing services, it has several weaknesses. First, the data was collected from customers of small and medium-sized restaurants in Bandung, Indonesia. As the region does not represent Indonesia as a whole, the outcome of this study cannot be generalized to other regions. It is suggested that the model used in this study be reassessed in different regions as well as in other restaurant types, such as luxury, large, or fast-food restaurants. Second, this study focused on the variables of e-service quality and food quality; however, other variables, such as involvement, image, trust, and socio-demographic factors, are potential determinants of customer satisfaction. Therefore, a study encompassing a larger set of variables would be 
worthwhile. Third, the actual causal relationships among the variables might not be represented by the model of online customer satisfaction proposed in this study, due to the cross-sectional method used. Therefore, it is suggested that future research use longitudinal data to determine if the relationships among variables change over time.

\section{REFERENCES}

Abou-Shouk, M. A., \& Khalifa, G. S. (2017). The influence of website quality dimensions on epurchasing behaviour and e-loyalty: a comparative study of Egyptian travel agents and hotels. Journal of Travel \& Tourism Marketing, 34(5), 6o8-623. doi: 10.1080/10548408.2016.1209151

Boyce, C., \& Neale, P. (2006). Conducting in-depth interviews: A guide for designing and conducting in-depth interviews for evaluation input.

Caruana, A., \& Ewing, M. T. (2010). How corporate reputation, quality, and value influence online loyalty. Journal of Business Research, 63(9), 1103-1110. doi: 10.1016/j.jbusres.2009.04.030

Chang, H. H., Wang, Y.-H., \& Yang, W.-Y. (2009). The impact of the quality of e-service, customer satisfaction and loyalty on e-marketing: Moderating effect of perceived value. Total Quality Management \& Business Excellence, 20(4), 423-443. doi: 10.1080/14783360902781923

Chang, S.-C., Chou, P.-Y., \& Lo, W.-C. (2014). Evaluation of satisfaction and repurchase intention in online food group-buying, using Taiwan as an example. British Food Journal, 116(1), 44-61. doi: 10.1108/BFJ-03-2012-0058

Chin, W. W., Peterson, R. A., \& Brown, S. P. (2008). Structural Equation Modeling in Marketing: Some Practical Reminders. Journal of Marketing Theory and Practice, 16(4), 287-298. Retrieved from http://www.jstor.org/stable/40470374

de Ruyter, K., Wetzels, M., Lemmink, J., \& Mattson, J. (1997). The dynamics of the service delivery process: A value-based approach. International Journal of Research in Marketing, 14(3), 231-243. doi: 10.1016/So167-8116(97)oooo4-9

Fandos, C., \& Flavián, C. (2006). Intrinsic and extrinsic quality attributes, loyalty and buying intention: an analysis for a PDO product. British Food Journal, 108(8), 646-662. doi: 10.1108/00070700610682337

Fornell, C., Johnson, M. D., Anderson, E. W., Cha, J., \& Bryant, B. E. (1996). The American Customer Satisfaction Index: Nature, Purpose, and Findings. Journal of Marketing, 6o(4), 7-18. doi: $10.2307 / 1251898$

Ha, J., \& Jang, S. (2010). Effects of service quality and the quality of food: The moderating role of atmospherics in an ethnic restaurant segment. International Journal of Hospitality Management, 29(3), 520-529. doi: 10.1016/j.ijhm.2009.12.005

Hahn, S.-E., Sparks, B., Wilkins, H., \& Jin, X. (2017). The quality of e-service Management of a Hotel Website: A Scale and Implications for Management. Journal of Hospitality Marketing \& Management, 26(7), 694-716. doi: 10.1080/19368623.2017.1309612

Hair, J. E., Hult, G. T., Ringle, C. M., \& Sarstedt, M. (2017). A Primer on Partial Least Squares Structural Equation Modeling (PLS-SEM) (2 ed.). Thousand Oaks: Sage.

Hair, J. F., Black, W. C., Babin, B. J., \& Anderson, R. E. (2010). Multivariate data analysis: A global perspective (7th ed.). Upper Saddle River: Pearson Education.

Han, H., \& Hyun, S. S. (2017). Impact of hotel-restaurant image and quality of physical-environment, service, and food on satisfaction and intention. International Journal of Hospitality Management, 63, 82-92. doi: 10.1016/j.jjm.2017.03.006 
Henseler, J., Ringle, C. M., \& Sarstedt, M. (2015). A new criterion for assessing discriminant validity in variance-based structural equation modeling. Journal of the Academy of Marketing Science, 43(1), 115-135. doi: 10.1007/s11747-014-0403-8

Hsin, C. H., \& Wang, H. W. (2011). The moderating effect of customer perceived value on online shopping behaviour. Online Information Review, 35(3), 333-359. doi: 10.1108/14684521111151414

Jeon, M. M., \& Jeong, M. (2017). Customers' perceived website service quality and its effects on eloyalty. International Journal of Contemporary Hospitality Management, 29(1), 438-457. doi: 10.1108/IJCHM-02-2015-0054

Kedah, Z., Ismail, Y., Haque, A., \& Ahmed, S. (2015). Key Success Factors of Online Food Ordering Services: An Empirical Study. Malaysian Management Review, 5o(2), 19-36.

Kim, J., Jin, B., \& Swinney, J. L. (2009). The role of etail quality, e-satisfaction and e-trust in online loyalty development process. Journal of Retailing and Consumer Services, 16(4), 239-247. doi: 10.1016/j.jretconser.2008.11.019

Kimes, S. E. (2011). Customer perceptions of electronic food ordering. Cornell Hospitality Report, 11(10), 6-15.

Lin, W., Ortega, D. L., \& Caputo, V. (2018). Are Ex-Ante Hypothetical Bias Calibration Methods Context Dependent? Evidence from Online Food Shoppers in China. Journal of Consumer Affairs, $o(0)$, 1-25. doi: 10.1111/joca.12202

Liu, W.-K., Lee, Y.-S., \& Hung, L.-M. (2017). The interrelationships among service quality, customer satisfaction, and customer loyalty: Examination of the fast-food industry. Journal of Foodservice Business Research, 20(2), 146-162. doi: 10.1080/15378020.2016.1201644

Namkung, Y., \& Jang, S. (2007). Does The quality of food Really Matter in Restaurants? Its Impact On Customer Satisfaction and Behavioral Intentions. Journal of Hospitality \& Tourism Research, 31(3), 387-409. doi: 10.1177/1096348007299924

Ng, S.-R., Wong, S.-Y., \& Chong, L. (2017). Outsourcing to Online Food Delivery Services: Perspective of F\&B Business Owners. Journal of Internet Banking and Commerce, 22(2), 1-13.

Nguyen, D. H., Leeuw, S., \& Dullaert, W. E. H. (2018). Consumer Behaviour and Order Fulfilment in Online Retailing: A Systematic Review. International Journal of Management Reviews, 2o(2), 255-276. doi:10.1111/ijmr.12129

Nisar, T. M., \& Prabhakar, G. (2017). What factors determine e-satisfaction and consumer spending in e-commerce retailing? Journal of Retailing and Consumer Services, 39, 135-144. doi: 10.1016/j.jretconser.2017.07.010

Oliver, R. L. (1999). Whence consumer loyalty? Journal of Marketing, 63, 33-44. doi: $10.2307 / 1252099$

Parasuraman, A., Zeithaml, V. A., \& Malhotra, A. (2005). E-S-QUAL:A Multiple-Item Scale for Assessing Electronic Service Quality. Journal of Service Research, 7(3), 213-233. doi: $10.1177 / 1094670504271156$

Pee, L., Jiang, J., \& Klein, G. (2018). E-store loyalty: Longitudinal comparison of website usefulness and satisfaction. International Journal of Market Research, January, 12, 1-17. doi: 10.1177/1470785317752045

Pham, T. S. H., \& Ahammad, M. F. (2017). Antecedents and consequences of online customer satisfaction: A holistic process perspective. Technological Forecasting and Social Change, 124, 332-342. doi: 10.1016/j.techfore.2017.04.003

Pigatto, G., Machado, J. G. d. C. F., Negreti, A. d. S., \& Machado, L. M. (2017). Have you chosen your request? Analysis of online food delivery companies in Brazil. British Food Journal, 119(3), 639657. doi: 10.1108/BFJ-05-2016-0207

Preacher, K. J., \& Hayes, A. F. (2004). SPSS and SAS procedures for estimating indirect effects in simple mediation models. Behavior Research Methods, Instruments, \& Computers, 36(4), 717731. doi: $10.3758 /$ bfo3206553 
Ryu, K., \& Han, H. (2009). Influence of the Quality of Food, Service, and Physical Environment on Customer Satisfaction and Behavioral Intention in Quick-Casual Restaurants: Moderating Role of Perceived Price. Journal of Hospitality \& Tourism Research, 34(3), 310-329. doi: 10.1177/1096348009350624

Sirgy, M. J., Efraty, D., Siegel, P., \& Lee, D.-J. (2001). A New Measure of Quality of Work Life (QWL) Based on Need Satisfaction and Spillover Theories. Social Indicators Research, 55(3), 241-302. doi: 10.1023/A:1010986923468

Statista. (2018). Food Delivery Worldwide Retrieved from https://www.statista.com/outlook/374/100/food-delivery/worldwide. Retrieved January 2oth, 2018 https://www.statista.com/outlook/374/10o/food-delivery/worldwide

Stokes, R., \& Frederick-Recascino, C. (2003). Women's perceived body image: relations with personal happiness. Journal of Women \& Aging, 15(1), 17-29.

Suhartanto, D. (2016). Tourist satisfaction with souvenir shopping: evidence from Indonesian domestic tourists. Current Issues in Tourism, 1-17. doi: 10.1080/13683500.2016.1265487

Suhartanto, D., Chen, B. T., Mohi, Z., \& Sosianika, A. (2018). Exploring loyalty to specialty foods among tourists and residents. British Food Journal, 120(5), 1120-1131. doi: 10.1108/BFJ-o9-20170485

Suhartanto, D., \& Leo, G. (2018). Small business entrepreneur resistance of ICT adoption: a lesson from Indonesia. International Journal of Business and Globalisation, 21(1), 5-18. doi: 10.1504/IJBG.2018.10015253

Sulek, J. M., \& Hensley, R. L. (2004). The Relative Importance of Food, Atmosphere, and Fairness of Wait: The Case of a Full-service Restaurant. Cornell Hotel and Restaurant Administration Quarterly, 45(3), 235-247. doi: 10.1177/0010880404265345

Trivedi, S. K., \& Yadav, M. (2018). Predicting online repurchase intentions with e-Satisfaction as mediator: a study on Gen Y. VINE Journal of Information and Knowledge Management Systems, o, 1-17. doi: 10.1108/VJIKMS-10-2017-0o66

Yeo, V. C. S., Goh, S.-K., \& Rezaei, S. (2017). Consumer experiences, attitude and behavioral intention toward online food delivery (OFD) services. Journal of Retailing and Consumer Services, 35, 150162. doi: 10.1016/j.jretconser.2016.12.013

Zeithaml, V. A., Parasuraman, A., \& Malhotra, A. (2002). Service quality delivery through web sites: A critical review of extant knowledge. Journal of the Academy of Marketing Science, 3o(4), 362. doi: 10.1177/009207002236911

Zikmund, W. G., Babin, B. J., Carr, J. C., \& Griffin, M. (2013). Business Research Methods (9th ed.). Mason, OH: South-Western, Chengage. 